60 Deve considerar-se a ordem pública na acepção administrativa do termo, isto é como sendo constiuido por um certo minimo de condiçós essenciais para uma vida social conveniente, ver, G. Vedel e P. Devolve, Direito administrativo, Vol. l, op. cit., p. 31.

61 C.C. № 87-149 L. 20 de fevereiro 1987. Rec. 22 62 Ver. M. Long e Al., Les grands arrêts de la jurispru-
dence administrative, $10^{\text {eme }}$ ed., Ėd. Dalloz, 1993, dence administ
p. $183 \mathrm{et} \mathrm{s}$.

630 problema colocava-se em termos diferentes na Constituição de 25 de Junho de 1975 pois a Comissao Permanente da Assembleia Popular podia assegurar a funçáa de Assemblela Popular entre os pe-

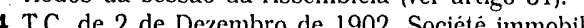

re de St-Just, Rec 713: D.P. 1903.31 , note Hauriou.

65 Decreto $n^{\circ}$ 5/93: Cria o Instituto Nacional de Viaçāo, B.R., 15 de Abril de 1993, I Série - № 15.

6 Decreto no 3/94: Cria o Instituto de Cereais de cambique, B.R., 11 de Janeiro de $1994,2^{\circ}$ Suplemento, I Série - № 1 .

67 Artigo 1 do Decreto no 3/94: Cria o Instituto de Cereais de Mocambique.

68 Poderiamos citar outros exemplos tais como a criacáo do Fundo Nacional do Turismo (Decreto no $10 /$ 93: Cria o Fundo Nacional do Turismo, B.R. 22 de Junho de 1993, 4º Suplemento, I Série - № 24; A modificaçáo dos estatutos do Fundo de Fomento à Pequena Industria aprovados pelo Decreto $\mathrm{n}^{\circ} 3 / 90$, de 12 de Março, B.R., 11 de Janeiro de 1994, Suplemento, I Sćrie - № 1 .
69 Decreto no 8/93: Procede ao ajustamento das taxas constantes da tabela anexa ao Regulamento do Imposto sobre os Combustiveis, B.R., 15 de Junho de 1993, Suplemento, i Série - № 23 .

$70 \mathrm{R}$. Chapus, Droit administratif général, op. cit., $\mathrm{n}^{0}$ 701 e s; D. Freitas do Amaral, Direito administrativo, Vol. III, op. cit., p. 20 e s. e 33 e s.

D. Freitas do Amaral, Direto administrativo, Vol. III, op. cit., p. 17 e 33.

2 Se encontrarmos a mesma formulação na Constituição de 25 de Junho de 1975. Os fundamentos não são exatamente os mesmos. Na Constituição de 25 de junho de 1975, o Presidente da República, embora nomeie o Primeiro-Ministro (a alinea b) do artigo 54), è organicamente diferenciado do Conseho de Ministros (Artigo 59). Na Constituiçáo mosma diferenciono o presidente da República é o "Chefe do Governo" (o numero 3 do artioo 117) 0 fundamento a propria existência do número 1 do artigo 150 só se pode conceber e justificar-se por um desdobra se pode função do órrão presidencial que pode a air como "Chefe do Estado" (Artigo 120), mas tambem como "Chefe do Governo" (Artigo 1211). Na área reservada à actividade do Presidente da República como "Chefe de Estado", o Governo deve "observar" as decisōes do Presidente que não foram tomadas a título de "Chefe do Governo", mas a titulo de "Chefe de Estado".

\title{
Reflexões Sobre a Interpretação Literal de Normas no Direito Tributário
}

ÍGOR DANILEVICZ

Professor de Direito Tributário da PUCRS e UFRGS. Mestrando em Direito na PUCRS

\section{SUMÁRIO}

1. Introdução; 2. Breves Consideraçōes Sobre a Idéia de Sistema; 3. Sistema x Literalidade; 4. Algumas Decisōes Sobre a Matéria; 5 , Conclusöes.

\section{RESUMO}

O problema da interpretação literal no Direito Tributário. É possivel sua utilização exclusiva em determinados casos apontados na lei? Sistema versus Literalidade. Decisōes sobre a matéria.

\section{ABSTRACT}

The problem of literal interpretation in Law Tax. Is it possible your exclusive utility in any cases indicated in the law? System versus Literal Method. Decisions about the subject.

\section{INTRODUÇão}

A proposta de reflexão - como o titulo está a indicar -, não foi outra do que a fixação do sentido e alcance do disposto no artigo 111 do Código Tributário Nacional - Lei n⿳0 5.172, de 25 10-1966 -, verbis: "Interpreta-se literalmente a legislação tributária que disponha sobre: I suspensão ou exclusão do crédito tributário; II - outorga de isenção; III - dispensa do cumprimento de obrigações tributárias acessórias."

Delimitado o objeto de nossa análise, faz-se imperativo tecer algumas considerações hermenêuticas preliminares. Assim, "a Hermenêutica tem por objeto investigar e coordenar por modo sistemático os principios cientificos e leis decor- rentes, que disciplinam a apuração do conteúdo, do sentido e dos fins das normas juridicas e a restauração do conceito orgânico do direito, para o efeito de sua aplicação: a Interpretação, por meio de regras e processos especiais, procura realizar, praticamente, estes principios e estas leis cientificas; a Aplicação das normas juridicas consiste na técnica de adaptação dos preceitos nelas contidos e assim interpretados às situaçoes de fato que se lhes subordinam."

Considerando a complexidade, a abrangência da vida, e as experiências como um todo devemos interpretar a simbologia posta para interagirmos com o meio e as pessoas. A simbologia aqui, deverá ser entendida na forma mais ampla possivel que a acepção da palavra permita, inclusive o silêncio - eis que até ele se interpreta, como afirma Emilio Caldara ("Interpretare è definire il significato di qualche cosa azione, leggi, contratti, parole, ecc. Tutto si può interpretare e in ogni modo: si interpretano concetti e le intenzione, si interpretano gli indizi, si interpreta anche il silenzio.")2 Nada demasiado termos à mão, alêm da lingüistica, a semiologia juridica.

É neste contexto que será feita a investigação sobre este que é um dos mais debatido enunciados do Sistema Tributário, despertando controvérsias não raro por equivocos na definição dos seus termos. 


\section{BREVES CONSIDERAÇÕES SOBRE A IDÉIA} DE SISTEMA

Da observação da norma suso mencionada pretende-se chegar a uma interpretação "conforme" o sistema juridico. Ou, como disse Ludwig Enneccerus, "interpretar uma expressão de Direito não é simplesmente 'tornar claro' o respectivo dizer, abstratamente falando; é, sobretudo, revelar o sentido apropriado para a vida real, e conducente a uma decisão reta." 3

Depreende-se da maciça doutrina hermenêutica, que a utilização exclusiva do método de "interpretação literal" é inadequada ou imprópria. Afirmar sua possibilidade de uso absoluto é sofismar - é assistemático. ${ }^{4}$ Com base nesta afir mação a priori. tentaremos desenvolver e comprovar no presente trabalho a sua validade enquanto proposição de uma lógica intra-sistêmica. 5

Importante ressaltar que, ao utilizarmos a expressão sistema, também temos presente um pensamento sistemático. Caracteristicas inerentes são a adequação valorativa e unidade interior do Direito, sintetizadas nas expressões ordem e unidade. Então chegaremos a uma definição de sistema juridico como ordem axiológica ou teleológica de principios juridicos gerais, moldada por Canaris. ${ }^{6}$

Visto por outro ângulo, poderemos dizer que um sistema juridico não é meramente formal ou dedutivo. Neste sentido convém trazer à colação a preciosa observação de Norberto Bobbio, para quem "Num sistema dedutivo, se aparecer uma contradição, todo sistema ruirá. Num sistema contradição, todo sistema ruira. Num sistema
juridico, a admissão do principio que exclui a incompatibilidade tem por conseqüencia, em caso de incompatibilidade de duas normas, não mais a queda de todo o sistema, mas somente de uma das normas ou no máximo das duas."7

Deste modo concebido o Direito em sua dinamicidade, resulta claro, em todos os seus ramos, que, para utilizar expressão consagrada, não devemos interpretar o fenômeno juridico $\mathrm{em}$ tiras. 0 que poderá ocorrer, quando alguém busca o sentido possivel de uma regra, analisandoa isoladamente, sem tentar encontrar seu elemento teleológico e, por conseguinte, ignorando o sistema? Poderá ser dada à literalidade um sentido que o legislador certamente não pretendeu, qual seja, o de leitura isolada do comando legal, quando literalidade parece querer dizer apenas interpretação o mais restritiva possivel.

De outra parte, surge a questão das contradiçōes de valores e de principios, que Canaris chama de aparentes "quebras no sistema". ${ }^{8} \mathrm{O}$ disposto no artigo 111 do Código Tributário Nacional parece se aproximar disto. De um lado, temos, no Direito posto, a determinação de utilizaçāo do método literal, quando se tratar de alguma das hipóteses ali previstas, I - suspensão ou exclusão do crédito tributário: II - Outorga de isencão; e III - dispensa do cumprimento de obrigaçōes tributárias acessórias. De outra parte, a hermenêutica jurídica demonstrando que a interpretação literal não constitui no único passo, senão o primeiro. A literalidade, quando muito, corresponderá a um prius lógico; e a exegese sistemática, um posterius antinomia imprópria, da espécie que sucede entre principios. Neste caso, haveria valores contrapostos. No assunto em tela, a norma indicada pelo Direito Tributário Positivo, opondo-se aparentemente à indicação doa Ciência do Direito. No entanto, trata-se de uma antinomia "solúvel", sendo que "a pressuposta incompatibilidade deriva de uma interpretação ruim, unilateral, incompleta ou errada de uma das normas. O jurista e o juiz tendem, tanto quanto possivel, à conservação das normas dadas."9

Se a diagnose estiver correta, o remédio a esta "quebra no sistema" será a interpretação literal iluminada pela exegese sistemática. ${ }^{10}$

\section{SISTEMA X LITERALIDADE}

Depreende-se, de uma forma ou de outra, que a utilização exclusiva do método literal de interpretação torna-se inadequado. Por que? Porque a percepção do Direito, enquanto sistema, dificultaria uma postura que podemos chamar intilizada, para considerar aquela posição em que eventualmente o intérprete, colocar-se-ia diante do caso concreto e da regra investigada. Não negamos a abstração das demais regras do sistema, para através de um "isolamento" identificarmos a regra aplicável ao caso concreto. Entretanto, tal abstração antes pressupõe do que exclui a utilização da totalidade do sistema à obtenção da regra aplicável à espécie. Neste sentido é que o saudoso e venerável Alfredo Augusto Becker asseverou que, "a regra contida na lei (fórmula literal legislativa) è a resultante lógica de um complexo de ações e reaçōes que se processam no sistema juridico onde foi promulgada. A lei age sobre as demais leis do sistema, estas, por sua vez, reagem; a resultante lógica é a verdadeira regra juridica da lei que provocou o impacto inicial." $" 11$ Ora, se é falsa a resultante lógica que conclui a partir da interpretação da "fór mula literal legislativa" isolada, não podemo dizer o mesmo quando a ilação resulta das açōes e reaçōes oriundas do "sistema" - ou ocorrida dentro do sistema. Nenhuma dedução de veracidade ou falsidade - resultando num sentido apropriado para a vida real - advirá se a mesma tiver origem fora do sistema. Ou seja - inevitável ser tautológico para clareza deste ponto -, a conclusão válida resultará necessariamente de uma lógica intra-sistêmica. Para que obtenhamos a "regra juridica" - aplicável ao caso concreto - , resultante da dinâmica imposta ao processo hermenêutico - ação e reação - fazse mister a compreensão de totalidade do "sistema juridico". Assim, levaremos em conta, por exemplo, os diversos princípios, institutos e categorias deste, cujos elementos integram o modelo em questão. Ou como disse Emilio Betti: "non può limitarsi a considerarne separatamente le parti in cui si articola, ma deve metterle in correlazione fra loro secondo il canone della totalitá."12

Esta dialética è imposta ao hermeneuta, justamente pela pluralidade do sistema. Das diversas teses e antiteses, extrairá a sintese. 0 que entendemos impossivel, se ao invés da pluralidade dos elementos do sistema, o exegeta trabalhasse na singularidade de uma "fórmula literal legislativa". Na particularidade excludente, não haveria dinâmica, mas regra jurídica estática. Haveria regra juridica e vácuo juridico circundante.

Em que pese o Código Tributário Nacional logo, também seu artigo 111 -, ter-se integrado ao ordenamento juridico no dia 01-01-1967 - data do inicio de sua vigência, conforme previsto no artigo 218 do referido diploma legal certamente o pensamento jurídico de então não infirmava a idéia de sistema. Porém, ainda que se sustentasse o contrário, a dinamicidade do Direito imporia mudanças. Neste sentido, lem bra o filósofo Miguel Reale que, "as transformacões havidas no mundo dos valores ou das valorações podem importar em interpretação nova e imprevista do mesmo texto legal, ainda que este continue formalmente imutável." 13

Conforma este entendimento o pensamento do tributarista Carlos da Rocha Guimarães. Tratando da interpretação literal prevista no artigo 111. notadamente acerca do inciso II, afirma que tal comando "não quer realmente negar que se pretação das leis concessivas de isenção, o processo normal de apuração compreensiva do sentido da norma, mas simplesmente impedir que se estenda a exoneração fiscal a casos semelhantes, alargando, além do seu exato limite, o que diz a letra da lei, sem, no entanto, deixar de incluir na interpretacão do interpretaçăo do todos os casos que a sua snificação indica como nele incluídos, sem o que a própria letra da lei também estaria ferida, e a exoeração, assim truncada, ficaria sem sentido."14 Qualquer que seja a nossa opção - entre vontade do legislador ou espirito da lei -, o seu fundamento deverá estar alicerçado em bases Juridico-epistemologicas sólidas. 0 que será obtido atravês da análise crítica das estruturas $\mathrm{e}$ elementos inerentes daquela premissa eleita. A bipolaridade mens legislatoris - mens legis è real ou aparente? É uma separação didática e de possivel coexistência dentro do sistema juridico? ${ }^{15}$

Não nos parece que 0 intérprete deva fazer tabula rasa, relativamente às "teorias relativas ao escopo próprio da interpretação", quando da utilização dos tradicionais métodos de interpretação (gramatical, sistemático e teleológico). Karl Engish nos ensina, que 0 casamento entre a determinação objetivista ou subjetivista do escopo interpretativo, com os tradicionais métodos de interpretação, será salutar. Somente assim poderão ser obtidas decisões seguras. ${ }^{16}$

No que tange à análise histórica de uma lei, nosso ponto de partida poderia ser o pensamento de então do legislador. Não olvidando a complexidade do pensamento humano - o legislador $\mathrm{e}$ seu pensamento de então - teriamos inevitavelmente de analisar outros aspectos. Dentre os quais, os fatos contemporâneos ao legislador. A situação sócio-econômica dele e do destinatário da regra; só para falar em alguns, pois admitimos como relevantes outros inúmeros fatos con- 
textuais - presente a natureza complexa do ser humano, não podemos resumi-lo simplesment a determinados aspectos, tais como: econômico, religioso, etc., sob pena de chegarmos a uma conclusão falsa. Neste sentido, o aspecto voluntarista tem demonstrado sua importância.

Lembremos, a propósito, da problemática envolvendo o representante comercial e a Lei $\mathrm{n}^{-}$ 7.713, de 22-12-1988, verbis:

"Art. 51. A isenção do imposto de renda de que trata 0 art. 11, item I, da Lei $n^{0} 7.256$ de 27-11-1984, não se aplica à empresa que se encontre nas situações previstas no art. $3^{0}$ itens I a V, da referida Lei, nem às empresas que prestem serviços profissionais de corretor, despachante, ator, empresário e produtor de espetáculos públicos, cantor, músico, médico, dentista, enfermeiro, engenhei ro, fisico, quimico, economista, contado auditor, estatistico, administrador, programador, analista de sistema, advogado, psicólogo, professor, jornalista, publicitário, ou assemelhados, e qualquer outra profissão cujo exercício dependa de habilitação profissiona exercicio dependa de
legalmente exigida."

legalmente exigida."
Do dispositivo mencionado, e do sistema em geral, não se infere a quebra da isenção tributária à atividade de representante comercial. Entretanto, posteriormente, foi expedido o Ato Declaratório Normativo CST $\mathrm{n}^{\circ} 24$, de 13-12-89, que definiu:

"Declara, em caráter normativo, às Superintendências Regionais da Receita Federal demais interessados, que a atividade de representação comercial, na intermediação de operaçoos por conta de terceiros, por ser assemelhada à de corretagem, exclui a sociedade que a exerce dos beneficios concedido à micro exerce di E o Ato Declaratório Normativo CST nº 25 ,

de 13-12-1989, diz

"Declara, em caráter normativo, às Superintendências Regionais da Receita Federal e demais interessados, que o representante comercial que exerce exclusivamente a mediação para a realização de negócios mercantis, como a define 0 art. $1^{\circ}$ da Lei $n^{\circ} 4.886$, de 09-12-1965, terá seus rendimentos tributados na pessoa fisica do beneficiário, uma vez não a tenha praticado por conta própria. Irrelevante a existência de registro como fir- ma individual na Junta Comercial e no Cadastro Geral de Contribuintes do Ministërio da Fazenda."

A análise e comparação simples de tais regramentos demonstra que a Lei $n^{0} 7.713 / 88$ em seu texto - apesar de ter sido transcrito somente 0 art. 51 - não contempla a atividade de representante comercial como passivel de triFederal, ao interpretar o texto legal, lançou mão da expressão "corretor... ou assemelhados" art. 51, Lei no $7.713 / 88$-, e concluiu pela eleição do representante comercial como contribuinte do referido imposto. Ressaltamos que o presente desenvolvimento restringe-se ao titulo proposto. Entretanto, não invalidamos a argumenpossivel envolvendo o principio de estrita legalidade tributária (artigo 150, inciso III, alinea "b" da Constituição Federal); proibição/limitaçāo da analogia em direito tributário (artigo 108 , inciso I, e $\S 1^{\circ}$ do Código Tributário Nacional); analogia por compreensão (interpretação extensival ou analogia por extensão (anadita); só para citar algumas. Mas, qual foi o pensamento do legislador histórico? Tributar tal atividade? Para buscarmos a mens legislatoris - e considerando que o "tempo não pára" -, devemos lançar mão de todos os elementos possiveis. De tudo que tenha estado o mais próximo possivel do intimo do legislador histórico. Relativamente ao exemplo em questa "buscou-se" o pensam questão, "buscou-se" o pensamento do legislador através do Diário do Congresso Nacional Seção I, pp. 3.321 - 3.324 -, do dia 21-9-1988, que traz na integra o Projeto de Lei $n^{0} 1.064$ / 88 , mais tarde transformado na Lei $\mathrm{n}^{0} \mathbf{7 . 7 1 3 /}$ 88, verbis: "A isenção do imposto de renda (...), não se aplica (...) nem às empresas que prestem serviços profissionais de corretor, despachante, serviços profissionais de corretor,

Ora, ainda que de relance, sem querer ser simplista, depreende-se que ao constar do Projeto de Lei o representante comercial como sujeito passivo de uma obrigação tributária; e após votacão final no processo legislativo, ter sido que a mens legislatoris é pela manutenção da enção fiscal.

A sensibilidade juridica do intérprete determinará o espaço a ser reservado à interpretação subjetiva. Já no tocante a interpretação objeti- vista, a mesma busca, não o voluntarismo interpretativo, mas a mens legis. Qual a intenção da lei? Qual a mensagem que a lei traz ao seu destinatário, independentemente da vontade $\mathrm{d}$ legislador? Se utilizarmos o exemplo legislativo anteriormente analisado sob a ótica voluntarista, agora pelo ângulo da teoria objetivista da interpretacão, certamente chegariamos à mesma conclusão - no sentido de manutenção da isenção do representante comercial. Entretanto, apesar desta - talvez - precipitada conclusão, iremos nos cingir à análise teórica da vontade provável da lei. E assim é que devemos considerá-la - mens legis. A lei será sempre avaliada de acordo com o sistema e o contexto existencial da mesma. 0 sentido da lei a ser perseguido será aquele que a ela se conforma. Aquele que reverbere o momento presente do univers a que pertence. Utilizando - aqui também - o métodos tradicionais de interpretação tendo em vista um escopo objetivista-interpretativo, 0 in térprete apreenderá uma parcela de represen tação do real.

O que efetivamente ocorre na interpretação da "lei", é a óbvia - porém nem sempre lembrada - existência de um sujeito em face da lei ou sujeitos - que chamamos de interprete, e "lei" - ou leis, sistema,... - enquanto objeto de análise, cujo resultado - conclusão - será uma representação do real.

0 produto da interpretação será a resultante do processo dialético estabelecido. Este produto terá a marca indelével da tábua de valores do intérprete, ainda que o mesmo procure colocar se em epoché (epoch), para obter o pensament do legislador ou da lei. Se alguém estranhar nossa afirmativa, no sentido da impossibilidade do intérprete tornar-se imune aos próprios valores no momento do ato interpretativo, devemos lembrar que foi a partir de Kant que a posição dos valores foi deslocada do objeto para sujeito. $^{17}$

Podemos considerar 0 ato de interpretar como elemento básico de um processo cognitivo - ao menos para o presente estudo. Possivelmente não 0 único, face à complexidade desta atividade mental. Ainda sobre o escopo interpretativo objetivista ou subjetivista, devemos ter presente que tal dicotomia serve muito mais ao entendimento do fenômeno, do que ao fenômeno em si. Ou seja, a relação entre ambas - objetivista e subjetivista -, está longe de ser maniqueista. Conforme procuramos demonstrar, 0 objeto lei a ser interpretada de acordo com o sistema - é complexo, bem como o sujeito também intérprete. Se a complexidade está presente, a utilização isolada de uma das duas hipóteses mencionadas fracassará. Não produzirá resuldade 0 fizemos de forma didática. Entendemos que deve haver uma interação entre ambas, no mais das vezes predominando uma hipótese.

Também neste sentido concordamos com Karl Larenz ao professar que "a cada uma destas teorias subjaz uma parte da verdade; por isso, nenhuma delas pode ser aceita sem limitacões." Antes, porem, ele faz retrospectiva histórica das duas teorias; lembrando serem adeptos do voluntarismo Windscheid, Bierling, Philipp Heck e Savigny; e imanentista à lei - i.e., interpretatioi ex-nunc e não ex-tunc - Kohler, Binding, Wach, Radbruch, Sauer e Binder. ${ }^{18}$ Encontramse numa posicão intermediária, segundo Engish o próprio Karl Larenz, mais Schreier, Bartholomeyczik e Dahm. ${ }^{19}$

A interpretação literal - de forma exclusiva -, historicamente demonstrou sua fragilidade irremediável. É imperiosa, pois, a função jurídica da interpretação, como critério do método interpretativo correto. 0 método cientifico norteará 0 trabalho do intérprete. Colocará à disposição do hermeneuta o instrumental necessário à obtenção do "sentido possivel" da lei.

\section{ALGUMAS DECISÕES SOBRE A MATÉRIA}

Parece-nos que a pragmática jurídica tem resolvido bem a questão. Neste sentido, uma simples retrospectiva histórica demonstra como 0 assunto tem sido tratado em nossos tribunais. Em meados do presente século, o Supremo Tribunal Federal decidiu, v.g.:

"IMPOSTO DE RENDA - ISENÇÃO FIS-

CAL — INTERPRETAÇÃO DA LEI

- A tributação é a regra e a isenção uma exceção, que precisa ser expressa.

- A interpretação estrita, ut verba sonnant, só é admissivel em matéria de exceção. Os principios admitem em geral interpretação por força de compreensão."

Companhia de Seguros "A Mannreim" versus União Federal. 
Ap. no 7.565 - Relator: Ministro José Linhares - Ac. unânime da $2^{\mathrm{a}}$ Turma do Suprem Tribunal Federal, em 19-10-1943. ${ }^{20}$

"ISENÇÕES FISCAIS - INTERPRETAÇĀO

- IMPOSTO DE RENDA - CARACTERIZAÇÃO DA RENDA

- As isençoes fiscais se interpretam sempre restritamente, o que aliás não impede a regra, sempre aplicável, da força de compreensão.

A renda de uma indústria não se confunde com a sua exploração, embora encontre nesta a sua fonte. O imposto de renda não incide na exploração nem grava o produto; incide na exploração nem grava o produto, recai no lucro da industria ou do trabalho."
União Federal versus Companhia SiderúrUnião Federal vers

Ap. $\mathrm{n}^{0} 7.339$ - Relator Ministro Orozimbo Nonato - Ac. unânime da $2^{\text {a }}$ Turma do Supremo Tribunal Federal, em 09-11-194321. Em momento mais recente, o Superior Tribunal de Justiça exarou decisões em que o problema da interpretação esteve presente.

Exemplificativamente podemos citar a decisão assim ementada:

"TRIBUTÁRIO. ISENÇÃO DO IMPOSTO SOBRE OPERAÇÕES DE CÂMBIO NAS IMPORTAÇÕES. DECRETO-LEI № 2.434 , DE 19.5.1988, ARTIGO $6^{\circ}$. A isenção tributária, como o poder de tributar, decorre do jus imperium estatal. Desde que observadas as regras pertinentes da Constituição Federal, pode a lei estabelecer critérios para o auferimento da isenção, como no caso in judicio.

"O real escopo do artigo 111 do Código Tributário Nacional nāo é o de impor a interpretação apenas literal - a rigor impossivel - mas, evitar que a interpretação extensiva ou outro qualquer principio de hermenêutica amplie 0 alcance da norma isentiva.

"Recurso unanimemente improvido."

(S.T.J., Relator Ministro Demócrito Reinal-

do, $1^{\text {a }}$ Turma, RESP. № 0012315-PE) $)^{22}$

\section{CONCLUSÕES}

Pelo exposto, temos elementos suficientes para entender a complexidade do texto legal, no que tange ao ato interpretativo - ou atos de interpretação. A simples leitura de úma palavra em um dispositivo legal, requer sua definição.
Num crescendo, teremos de identificar o conunto de palavras que compõem um artigo; buscar o sentido possivel do texto, o que fatalmente nos obrigará a "conhecer" 0 contexto - não olvidando que a mesma palavra possui normalmente vários significados.

Está claro que não repudiamos o método literal de interpretação. 0 que sustentamos é a impossibilidade de sua utilização exclusiva e isolacionista, pois, convém enfatizar, "toda a interpretação de um texto há de se iniciar com o sentido literal." ${ }^{23}$ Iniciar-se pressupõe um desenvolvimento, e não um fim em si mesmo. 0 desenvolvimento terá como limite o sentido possivel da lei. Agora, para encontrarmos o sentido possivel da lei, buscaremos este desiderato através das teorias relativas ao escopo da interpretação, e dos tradicionais métodos interpretativos. Este conjunto de teorias e métodos podemos unificar em torno da expressão "método". E utilizando o "método" "teleológico-objetivo", "teleológico-subjetivo", "gramatical-subjetivo", etc., poderemos erguer a ponta do véu de Î́sis $\mathrm{e}$ etc., poderemos erguer

Com relação ao devir, o hermeneuta invocará os métodos de interpretação existentes e através do processo cognitivo alcançara a sua representação do real - ou do conhecido que se aproxima do real. E com um pouco de inspiração, repensará o sistema, visto que o Direito é dinâmico.

\section{NOTAS DE REFERÊNCIA}

1 Ráo, Vicente. O Direito e a Vida dos Direitos. São Paulo Max Limonad, 1960, p. 542.

2 Aut. cit. in Interpretazione delle Leggi. Milano, Società Editrice Libraria, 1908, p. 4

3 Apud Carlos Maximiliano, op. cit., p. 10

Sonsmas como "argumentos que parecem sê-lo, mas que deveras sáo paralogismos e não argumentos." E, paralogismo, como argumento "baseado em proposiçōes que, embora adequadas à ciência em causa, não são evidentes. Aristôteles, Organon. Lisboa: Guimaråes Editores, 1986 e 1987, vol. VI, Elencos Sofisticos, vol. V, Tópicos, pp. 09 e 11 , respectivamente.

5 Lógica intra-sistêmica no sentido de conexão intrinseca de pensamentos, conforme prefere e/ou utiliza Karl Engish, quando diz: "Essencial è e será que no sentido logico, a conexão intrinseca dos pensamentos junidicos a come aquela premissa masor con dela, a conclusão" Aut Cit. in Introducio ao Penso- mento Jurídico. Lisboa: Fundação Calouste Gulbenkian, 1988, pp. 122-123.

Claus-Wilhelm Canaris. Pensamento Sistematico e Conceito de Sistema na Ciência do Direito. Lisboa: Fundação Calouste Gulbenkian, 1989, p. 283: "Sistema como uma ordem teleológica (aberta e fundamentalmente imóvell, logo dai resulta que $o$ argumento sistemático apenas representa uma forma especial de fundamentaçāo teleológica." "Aberto. Isto vale tanto para o sistema de proposiçōes doutrinárias ou 'sistema cientifico', como para o próprio sistema da ordem juridica, o 'sistema objetivo'. A proposito do primeiro, a abertura significa a incompletude do conhecimento cientifico, e a propósito do ultimo, a mutabilidade dos valores juridicos fundamentais. Mobilidade. No sentido que este termo recebeu de Wilburg, significa a igualdade fundamental de categoria e a mútua substituibilidade dos critérios adequados de justiça, com a renuncia simultânea à formação das." (pp. 281-282)

7 Aut. cit. in Teoria do Ordenamento Juridico. Brasilia: 8 Id., p. 285.

9 Aut. e op. cit., pp. 85-92, 102-105.

10 Id., p. 280: Devemos lembrar que Canaris não é es-
. truturalista, mas funcionalista. Preocupa-se em buscar um conceito de sistema que possa cumprir uma função significativa na Ciência Jurídica.

11 Aut. cit., in Teoria Geral do Direito Tributário. São Paulo: Saraiva, 1972, p. 104. Becker quando fala no lo: Saraiva, 1972, p. 104. Becker quando fala no ridico", tem presente que "toda norma é, com efeito, parte integrante do sistema juridico a que pertence. Desde o momento da sua criação, entre todas a normas de um mesmo sistema se exerce um complexo de açōes e reaçōes, que decorrem da necessária amalgamaçáa das normas no ordenamento vigente. Já foi exatamente observado que a norma Juricica isolada não existe como tal na realidade $d a$ vida juridica. Toda norma é valida e obrigatorna.

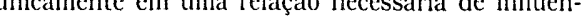
cias reciprocas com um número ilimitado de outras normas, que a determinam mais expressamente, que a limitam, que a completam de modo mais ou medefinitiva conquista o conceito da unidade e imanência de toda a lei vigente." id., p. 105.

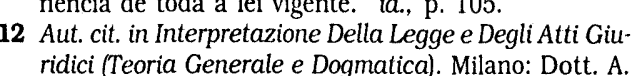
Giuffré-Editore, 1949, p. 257

13 Aut. cit., in Miguel Reale na UnB. Brasilia: Coleção Itinerários, Universidade de Brasilia, 1981, p. 75. 4 Aut. cit., artigo escrito na coletânea "Proposicōes Tributárias", organizada em memória de Rubens Gomes de Souza. São Paulo: Resenha Tributária, 1975, pp. 59, 61, apud Luiz Antonio Mattos Pimenta Araujo. Interpretaça de Isenção Objetlua. São Paulo: Revista da Faculdade de Direito da Universidade de São Paulo, vol. 83/88, p. 171

5 Luiz Fernando Coelho, examinando a Jurisprudência tradicional, salienta que "...procurando identificar-se a realidade imaginada do direito, ou seja, a sua ideologia, com dados empiricos, por exemplo, a vontade do legislador, a intenção da lei, a vontade do estado, como se fosse possivel reconstituir a vontade real de um legislador que ja morreu, ou a inmesmo a vontade de uma ficço." ath e op. cit. 209 .

16 Aut. e op. cit., p. 183.

Não pode o intérprete ficar infenso aos seus próprios valores. "O valor, para toda a Filosofia antiga e clássica, era algo que estava nas coisas." A partir de Immanuel Kant deslocou-se para o sujeito. Vide sofí. São Paulo: Ática, 1986, p. 82

18 Aut. cit., in Metodologia da Ciência do Direito. Lisboa: Fundaçāo Calouste Gulbenkian, 1989, pp. 380-381, relativamente a Savigny, p. 19.

19 Aut. e op. cit.. pp. 172-173.

20 Revista Forense, vol. 102/71.

21 Revista Forense, vol. 100/59.

22 DJ. 03-2-92, p. 436.

23 Karl Larenz, op. cit., p. 385 